\title{
Selective Association between Cephalosporin, Quinolone, Macrolide, and Penicillin Antibiotic Consumption and Childhood Obesity in Europe
}

\author{
Gabor Ternak ${ }^{1}$ Zs Edel'2, Zs Feiszt ${ }^{3}$, J. Szekeres ${ }^{4}$, B. Visegrady5, I. Wittmann² \\ ${ }^{1}$ Faculty of Medicine, Chair of Migration Health, University of Pécs, Pécs, Hungary \\ ${ }^{2}$ Faculty of Medicine, Second Department of Internal Medicine and Nephrology Centre, University of Pécs, \\ Pécs, Hungary \\ ${ }^{3}$ Faculty of Medicine, First Department of Internal Medicine, Department of Infectology, University of Pécs, \\ Pécs, Hungary \\ ${ }^{4}$ Faculty of Medicine, Department of Medical Microbiology and Immunology, University of Pécs, Pécs, Hungary \\ ${ }^{5}$ Faculty of Medicine, Department of Biophysics, University of Pécs, Pécs, Hungary \\ Email: gabor.ternak@aok.pte.hu
}

Received 17 August 2015; accepted 17 October 2015; published 20 October 2015

Copyright (c) 2015 by authors and Scientific Research Publishing Inc.

This work is licensed under the Creative Commons Attribution International License (CC BY).

http://creativecommons.org/licenses/by/4.0/

(c) (i) Open Access

\section{Abstract}

The accelerated weight gain in productive animals as a result of feeding antibiotic enriched fodder has been well known for decades. The better energy harvest is the result of modified gut microbiota as a consequence of applied antibiotics. Similar mechanisms might result obesity in humans as well. Objectives: Finding associations between global antibiotic consumption of different classes in EU countries and obesity data in adults and children prove that antibiotics might play a significant role in the development of obesity "epidemics" and related illnesses. Methods: Antibiotic consumption data were compared with obesity figures in adults and children in European countries and statistically analyzed for significance. Results: Significant correlation was found between the average yearly consumption of cephalosporins $(p=0.007)$, quinolones $(p=$ 0.031), macrolides ( $p=0.000083$ ) and childhood obesity data, but no significant association was observed with the average penicillin consumption. No association was observed between adult obesity and any of the antibiotic classes studied. Conclusions: Our results support the hypothesis that different types of antibiotics might influence the development of obesity among children, and this finding can serve as a unified explanation for the development of obesity "epidemics", similarly to the obesity and gut flora alteration-related diseases (type 2 diabetes mellitus, autism, etc.). 


\section{Keywords}

Antibiotic Consumption, Cephalosporin, Quinolone, Macrolide, Penicillin, Childhood Obesity, Adult Obesity

\section{Introduction}

The discovery of antibiotics in the mid-twentieth century has contributed to the increased estimated life span. Soon, it was realized that several microbes were capable of developing antimicrobial resistance, and new pathogens emerged producing new diseases while the old ones kept coming back.

Antibiotics have been used to promote growth and enhance performance of livestock for over decades. In the USA, low doses of antimicrobials are fed to large numbers of animals to accelerate weight gain by as much as $15 \%$ [1]. The gut microbiota plays an important part in the harvesting of energy and laboratory simulations have revealed that antibiotic treatment alters the composition of the gut microbiota and the host response to specific microbial signals [2].

The mechanisms by which antibiotics improve growth/obesity are not clearly understood. The gut microbiota has been linked to low-grade inflammation through activation of innate immunity through the LPS-Toll-like receptor 4 axis. Cani et al. demonstrated that mice fed a high-fat diet for 2 to 4 weeks exhibited a significant increase in circulating LPS levels (described as "metabolic endotoxemia") and that these mice became obese and had obesity associated metabolic disorders [3]. Similarly, mice infused with LPS (to reach levels observed in mice that were fed a high-fat diet) also had obesity and obesity-associated metabolic disorders. When metabolic endotoxemia was reproduced by subcutaneous infusion of LPS, animals developed the same metabolic abnormalities induced by the high-fat diet, while LPS receptor KO (CD14KO) mice were resistant to the effects of both high-fat diet and LPS infusion. Moreover, CD14KO mice were hypersensitive to insulin even when they were fed a normal diet, suggesting that CD14 might modulate insulin sensitivity in physiological conditions. Obesity has further been shown to be associated with altered gut microbial composition in human subjects and mice. The guts of obese human subjects were shown to have reduced numbers of Bacteroidetes and increased numbers of Firmicutes compared with those of their lean counterparts [3] [4].

Weight gain was observed as a result of applying erythromycin in preterm neonates (born at less than 32 weeks' gestation) with feeding intolerance [5].

The hypothesis that antibiotics might have the same global effect on humans than in livestock was first raised in 2005 [6], because antibiotics being acquired either as treatment or from the environment as antibiotic pollution could alter the gut flora in humans also, and due to similar mechanisms, outlined above, obesity/growth might develop.

\section{Objectives}

The observation that antibiotics administered in low doses have been used as growth promoters in the agricultural industry since the 1950s prompts us to compare data bases of global antibiotic consumption in European countries, compiled and published by the ESAC project (European Surveillance of Antibiotic Consumption) and current obesity prevalence among children and adults (OECD, WHO, etc.) seeking for possible significant statistical associations. As several recent publications indicated the association of the childhood obesity/growth and antibiotic consumption, and even experimental researches supported this concept [7]-[11], we wanted to establish a possible statistical correlation between different classes of antibiotics and childhood/adult obesity as well. According to our working hypothesis, if significant positive correlation can be established between those databases, it might be a clear indication that antibiotics (consumption/pollution) are capable influencing human obesity in a global manner. We want to elucidate, as much as possible, that quantitative or qualitative (probably both) consumption data are corresponding to obesity figures (adults and children) or not.

\section{Materials and Methods}

\subsection{Study Design}

Cumulative data were obtained from the publications describing global outpatient antibiotic consumptions in EU 
[12] and different classes of outpatient antibiotic consumption in European countries between 1997-2009 [13]-

[16]. Not all the 33 countries included in the publications reported their consumption to the ESAC project in every year (covering 1997 through 2009). Average consumption/year for cephalosporins, quinolones, penicillin and macrolides for each of the countries was calculated and entered in a datasheet. The data obtained were based on the reported numbers of years of the respective countries (minimum 1 year, maximum 13 years) and expressed in DIDs (defined daily dose/1000 inhabitants/day).

Detailed comparisons were made within the penicillin group for narrow spectrum penicillin (NSP) including penicillinase resistant penicillin (PRP) to obesity prevalence and the broad spectrum penicillins (BSP) including beta-lactamase combined penicillin (COP).

Obesity figures for children and adults were acquired mostly from OECD and WHO statistics, but other sources were also considered. The obesity prevalence was expressed in percentage (\%) and reflected the obesity situation in the reported countries for the year of 2010 or the nearest year. When the obesity prevalence among boys and girls were different, an average number was established and included in the datasheet. Overweight $\left(\mathrm{BMI}>25 \mathrm{~kg} / \mathrm{m}^{2}\right)$ and obesity $\left(\mathrm{BMI}>30 \mathrm{~kg} / \mathrm{m}^{2}\right)$ were counted together [17]-[23].

\subsection{Statistics}

Rank correlation was calculated between obesity prevalence (\%) in adults and children and the average yearly consumption of cephalosporins, quinolones, penicillin and macrolides (DID).

\section{Results and Discussion}

The average yearly antibiotic consumption in the four major classes of antibiotics included in the study was estimated as 493.99 DID/year (cephalosporins: 68.48 DID/13.86\%/, quinolones: 49.4 DID/10\%/, penicillin: 290.92 DID/58.89\%/, macrolides: 85.19/14.24\%/). Those consumption data were separately compared to the obesity data of children and adults in all the 33 countries providing the antibiotic consumption figures. Compared to childhood obesity, the correlation (R) for cephalosporins was $0.460(p=0.007)$, for quinolones $0.375(p=$ $0.031)$, for macrolides: $0.630(p=0.000083)$ indicating strong, significant correlations. As for the penicillin group the correlation was $0.239(p=0.18)$ which means, that no association can be established between childhood obesity and penicillin consumption (Figure 1).

No association was found in any antibiotic category compared to adult obesity figures: for cephalosporins the correlation (R) proved to be $0.203(p=0.256)$, quinolones $-0.127(p=0.480)$, macrolides $0.096(p=0.594)$, penicillin $0.252(p=0.156)$ (Figure 2). Detailed data by countries are included in Table 1.

The detailed analysis of the penicillin group yielded no correlation between the average penicillin consumption $(\mathrm{R}=0.24, p=0.18)$ or the "NSP-PRP" penicillin consumption $(\mathrm{R}=0.27, p=0.13)$ and the obesity in children. In the case of "BSP + COM" antibiotics and the obesity in children moderate positive correlation ( $\mathrm{R}=$ $0.34, p=0.05$ ) was found.

In the case of penicillin consumption we did not find even weak positive correlation between average penicillin consumption ( $\mathrm{R}=0.25, p=0.15)$ or the broad spectrum penicillin ("BSP + COM") consumption ( $\mathrm{R}=0.24, p=$ 0.17 ) and the obesity in adults. We did not find any correlation between the narrow spectrum penicillin ("NSP + PRP”) consumption and the obesity in adults $(\mathrm{R}=0.015, p=0.93)$ either. Detailed data by countries and penicillin groups are found in Table 2.

We have observed that childhood obesity is rather associated with qualitative parameters of antibiotic consumption, than to quantitative figures. In spite of the fact, that the majority of antibiotic consumption (58.89\%) was related to the penicillin group, no statistical significance was found between childhood obesity and penicillin consumption. The strongest significance was establishes with the macrolide group (14.24\%) and obesity.

Our original working hypothesis was that if antibiotics alter the gut flora which promotes more „energy harvest" it might have been observed among adults as well, but our results were very conclusive in each of the antibiotic groups between adults and children that only children are affected.

The International medical community is currently facing an unprecedented high speed epidemic of obesity and type 2 diabetes mellitus (T2DM) along with the unexplained increase of some more different ailments, like autism, of which we are not able to come out with an appropriate explanation [24]. Experimental data clearly established the probable mechanism and relationship between gut flora and antibiotic consumption, because antibiotics, by altering the gut flora, will increase the "energy harvest" from the intestine. Similar changes can be 
Table 1. Cumulative datasheet for antibiotic consumption (average/year in DID for the years available) and obesity prevalence among children and adults [12]-[23].

\begin{tabular}{|c|c|c|c|c|c|c|}
\hline $\begin{array}{c}\text { Antibiotics } \\
\text { (in DIDs/year) }\end{array}$ & Cephalosporins & Quinolones & Penicillin & Macrolides & \multirow{2}{*}{$\begin{array}{c}\text { Obesity in children of } \\
\text { various age } 2010 \\
\text { or nearest year }(\%)\end{array}$} & \multirow{2}{*}{$\begin{array}{c}\text { Obesity in adults } \\
2010 \text { or nearest } \\
\text { year (\%) }\end{array}$} \\
\hline Country & Average & Average & Average & Average & & \\
\hline Austria & 1.6 & 1.32 & 5.37 & 2.93 & 18 & 12.8 \\
\hline Belgium & 3.1 & 2.36 & 11.31 & 2.84 & 15.5 & 13.8 \\
\hline Bulgaria & 1.87 & 1.49 & 8.64 & 1.34 & 28.2 & 11.5 \\
\hline Croatia & 3.31 & 1.44 & 10.67 & 2.31 & 16.5 & 22.3 \\
\hline Cyprus & 6.5 & 4.02 & 15.28 & 3.54 & 20.1 & 15.6 \\
\hline Czech Republic & 0.97 & 1.17 & 7.27 & 2.76 & 15.5 & 17.4 \\
\hline Denmark & 0.03 & 0.3 & 8.62 & 2.2 & 18 & 13.4 \\
\hline Estonia & 0.72 & 0.76 & 4.62 & 1.6 & 16 & 16.9 \\
\hline Finland & 2.28 & 0.8 & 5.66 & 1.68 & 21.5 & 15.6 \\
\hline France & 3.69 & 2.07 & 15.59 & 4.05 & 15 & 12.9 \\
\hline Germany & 1.29 & 1.14 & 4.39 & 2.15 & 20 & 14.7 \\
\hline Greece & 7.24 & 2.08 & 11.1 & 8.38 & 41 & 17.3 \\
\hline Hungary & 2.27 & 1.46 & 8.03 & 2.65 & 25.5 & 28.5 \\
\hline Iceland & 0.42 & 0.67 & 10.66 & 1.58 & 17 & 21 \\
\hline Ireland & 0.97 & 0.77 & 9.83 & 2.92 & 22 & 23 \\
\hline Israel & 3.08 & 1.2 & 11.67 & 1.64 & 26 & 26 \\
\hline Italy & 1.9 & 3.13 & 12.7 & 4.96 & 35 & 10.3 \\
\hline Latvia & 0.18 & 0.97 & 5.29 & 0.9 & 10 & 16.9 \\
\hline Lithuania & 1.78 & 1.27 & 13.02 & 1.67 & 9 & 19.7 \\
\hline Luxembourg & 4.97 & 2.41 & 11.1 & 3.81 & 22.5 & 22.5 \\
\hline Malta & 4.45 & 1.71 & 8.94 & 3.38 & 33.3 & 22.9 \\
\hline Netherlands & 0.07 & 0.86 & 4.02 & 1.27 & 16 & 11.4 \\
\hline Norway & 0.21 & 0.42 & 6.63 & 1.69 & 14.5 & 10 \\
\hline Poland & 2.2 & 1.12 & 9.45 & 2.43 & 14 & 15.8 \\
\hline Portugal & 3 & 3.15 & 11.57 & 3.68 & 28 & 15.4 \\
\hline Romania & 2.47 & 1.26 & 4.31 & 1.83 & 14 & 7.9 \\
\hline Russian Federation & 0.29 & 1.57 & 2.84 & 1.12 & 17 & 16 \\
\hline Slovakia & 2.96 & 1.68 & 13.12 & 4.14 & 15 & 16.9 \\
\hline Slovenia & 0.63 & 1.28 & 10 & 2.91 & 27.5 & 16.8 \\
\hline Spain & 2.03 & 2.26 & 11.09 & 2.58 & 25 & 16 \\
\hline Sweden & 0.45 & 0.98 & 7.12 & 0.6 & 17 & 12.9 \\
\hline Switzerland & 0.75 & 1.8 & 3.84 & 1.25 & 18 & 8.1 \\
\hline UK & 0.8 & 0.48 & 7.17 & 2.4 & 24 & 26.1 \\
\hline
\end{tabular}


Table 2. Consumption of broad spectrum penicillin (broad spectrum penicillin/BSP/+ beta-lactamase-combined penicillins/ $\mathrm{COP} /$ ) and narrow spectrum penicillin (narrow spectrum penicillin/NSP/+ penicillinase resistant penicillin /PRP/) in comparison to obesity prevalence among children and adults.

\begin{tabular}{|c|c|c|c|c|c|}
\hline \multicolumn{6}{|l|}{ Penicillin (in DID) } \\
\hline Country & $\begin{array}{c}\text { Average } \\
\text { consumtion in DID }\end{array}$ & $\mathrm{BSP}+\mathrm{COM}$ & NSP + PRP & $\begin{array}{c}\text { Obesity } \\
\text { in child. }(\%)\end{array}$ & $\begin{array}{c}\text { Obesity } \\
\text { in adults (\%) }\end{array}$ \\
\hline Austria & 5.37 & 4.22 & 1.15 & 18 & 12.8 \\
\hline Belgium & 11.31 & 10.92 & 0.41 & 15.5 & 13.8 \\
\hline Bulgaria & 8.64 & 7.17 & 1.49 & 28.2 & 11.5 \\
\hline Croatia & 10.67 & 9.25 & 1.42 & 16.5 & 22.3 \\
\hline Cyprus & 15.28 & 15.14 & 0.15 & 20.1 & 15.6 \\
\hline CzechRepublic & 7.27 & 5.04 & 2.23 & 15.5 & 17.4 \\
\hline Denmark & 8.62 & 2.79 & 5.82 & 18 & 13.4 \\
\hline Estonia & 4.62 & 4.3 & 0.32 & 16 & 16.9 \\
\hline Finland & 5.66 & 3.77 & 1.89 & 21.5 & 15.6 \\
\hline France & 15.59 & 14.9 & 0.69 & 15 & 12.9 \\
\hline Germany & 4.39 & 2.98 & 1.41 & 20 & 14.7 \\
\hline Greece & 11.1 & 10.31 & 0.79 & 41 & 17.3 \\
\hline Hungary & 8.03 & 7.04 & 0.99 & 25.5 & 28.5 \\
\hline Iceland & 10.66 & 6.52 & 4.14 & 17 & 21 \\
\hline Ireland & 9.83 & 8.14 & 1.69 & 22 & 23 \\
\hline Israel & 11.67 & 10.08 & 1.59 & 26 & 26 \\
\hline Italy & 12.7 & 12.66 & 0.04 & 35 & 10.3 \\
\hline Latvia & 5.29 & 5.13 & 0.16 & 10 & 16.9 \\
\hline Lithuania & 13.02 & 9.4 & 3.63 & 9 & 19.7 \\
\hline Luxembourg & 11.1 & 10.76 & 0.34 & 22.5 & 22.5 \\
\hline Malta & 8.94 & 8.83 & 0.12 & 33.3 & 22.9 \\
\hline Netherlands & 4.02 & 3.27 & 0.75 & 16 & 11.4 \\
\hline Norway & 6.63 & 2.13 & 4.49 & 14.5 & 10 \\
\hline Poland & 9.45 & 8.8 & 0.66 & 14 & 15.8 \\
\hline Portugal & 11.57 & 10.89 & 0.68 & 28 & 15.4 \\
\hline Romania & 4.31 & 4.01 & 0.3 & 14 & 7.9 \\
\hline Russian Federation & 2.84 & 2.72 & 0.11 & 17 & 16 \\
\hline Slovakia & 13.12 & 8.97 & 4.14 & 15 & 16.9 \\
\hline Slovenia & 10 & 7.49 & 2.51 & 27.5 & 16.8 \\
\hline Spain & 11.09 & 10.73 & 0.35 & 25 & 16 \\
\hline Sweden & 7.12 & 1.56 & 5.57 & 17 & 12.9 \\
\hline Switzerland & 3.84 & 3.55 & 0.29 & 18 & 8.1 \\
\hline UK & 7.17 & 5.64 & 1.53 & 24 & 26.1 \\
\hline
\end{tabular}



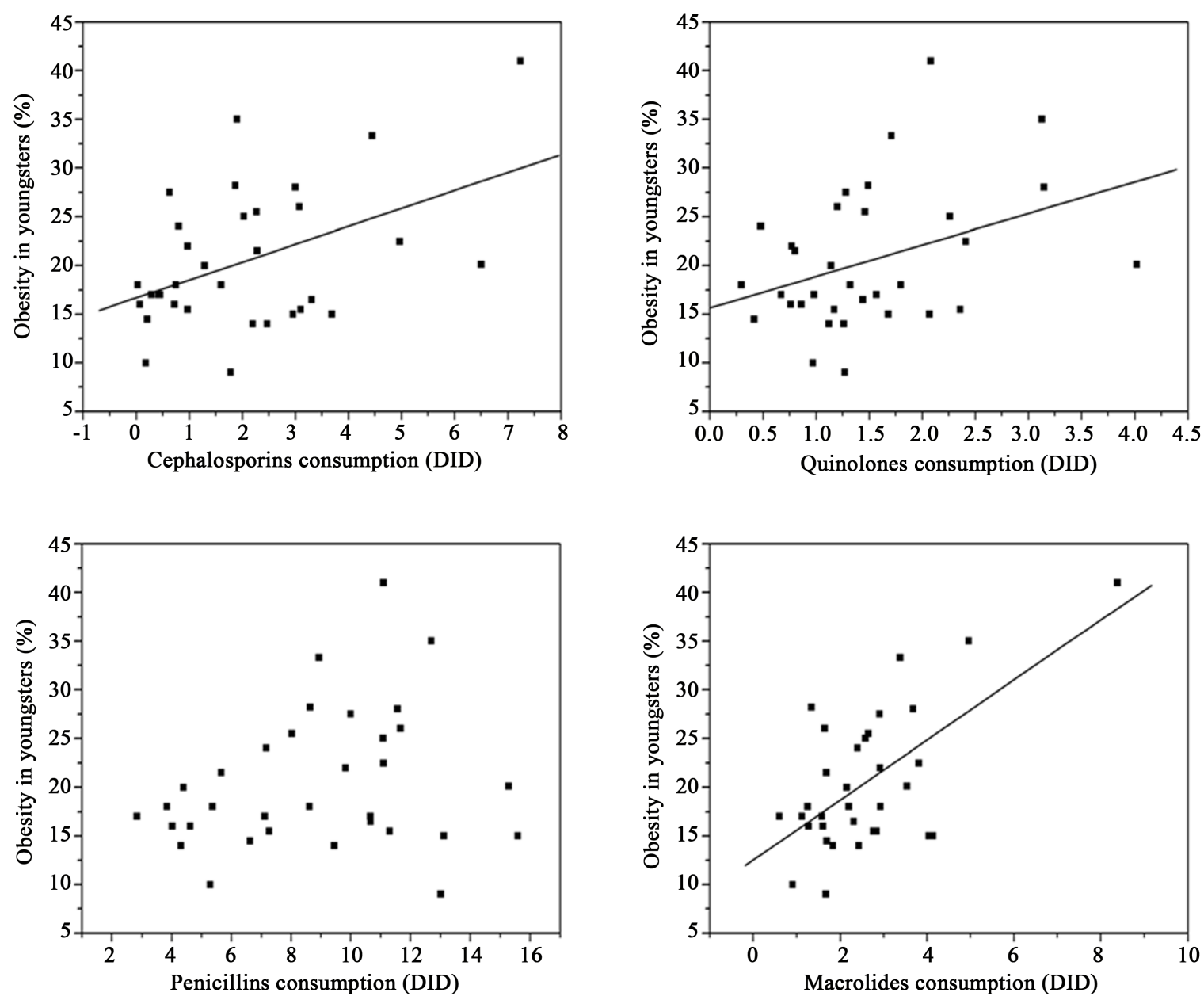

Figure 1. Significant correlation can be observed between the average/year consumption (in DID) of cephalosporin, quinolone and macrolide group of antibiotics and childhood obesity, but no similar association found with the average consumption of penicillin group.

achieved by probiotics also [25]. Human observations supported the mechanisms of developing obesity described in experimental animals, and clinical observations proved that children receiving antibiotics in their first 6 month of life have 22 percent more chance developing increased BMI (11). Our comparative analysis of databases and the recent publications clearly indicate the possibility of the association between human antibiotic consumption and obesity in children. The relationship between obesity and T2DM was established for decades. The observed "epidemics" of obesity and T2DM particularly among children are clearly parallel with the increased antibiotic use and of the increasing antibiotic pollution, which might provide a permanent, low grade antibiotic pressure on the gut flora from the environment.

Our findings confirmed previous observations of obesity promoting the effect of macrolides and other classes of antibiotics but penicillin [5] [7] [8] [11].

The ever increasing utilization of broad-spectrum antibiotics might select resistant bacteria and results overgrow of other species (Firmicutes and C. difficile, etc.) together with the elimination of the so called "bacteriocin" producing bacteria population from the gut flora as well, which helps the overgrow also. It is of interest that 3 classes of antibiotics showed significant correlation to the prevalence of childhood obesity, but in the group of penicillin, only moderate positive (with broad spectrum penicillin) and no correlation (with narrow spectrum penicillin) were observed, and no significance was found to the cumulative consumption of the penicillin group either.

The prevalence of adult obesity was not associated with the antibiotic consumption in any of the classes of the antibiotics compared. 

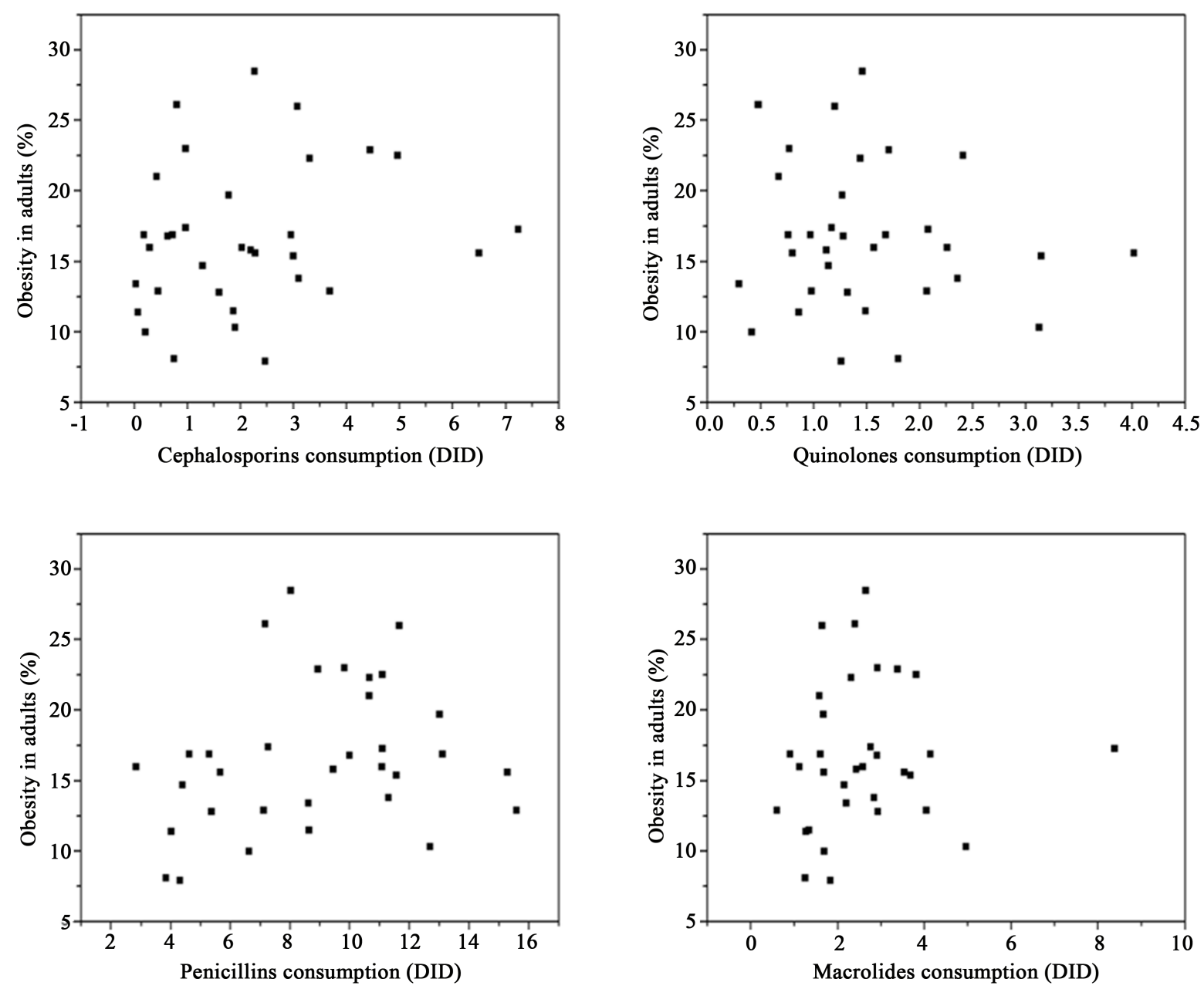

Figure 2. No similar association found between the average consumption of different groups of antibiotics and adult obesity.

Recent researches revealed the alteration of human microbiota in certain diseases, such as diabetes mellitus, sclerosis multiplex, autoimmune disorders, and even in cardiovascular diseases (atherosclerosis). The most interesting is the alteration of the human microbiota with bacterial overgrow of Desulfovibrio species and others in autism [26] [27]. The spreading of autism shows the same epidemiological pattern as obesity and T2DM, and even the $20 \%$ of autistic children are obese often suffering of gastrointestinal complains. Attempts were made to achieve improvement by reconstructing the intestinal flora via fecal microbiota transplantation (FMT) in the cases of sclerosis multiplex and T2DM. The amelioration of the symptoms and the improvement of insulin resistance were achieved in many cases [28] [29].

\section{Conclusions}

Accepting the well documented fact that antibiotics are capable of influencing human gut flora [30] and this altered gut flora might play a role in the development of different diseases, we can consider the effect of antibiotics as a common denominator in the development of very different diseases (like obesity, T2DM, autism, sclerosis multiplex, etc.) in susceptible subjects, but other circumstances (genetics, environment, etc.) cannot be disregarded either.

Our results, when comparing crude databases of antibiotic consumption and obesity, clearly demonstrate the association between obesity and antibiotic consumption among youngsters, but similar correlation is not found in adults.

The radical limitation of the use of certain broad spectrum antibiotics in children might reduce the spreading 
of obesity epidemics and other gut flora-related diseases, like autism. Another alternative is the extensive utilization of FMT in different cases of altered gut flora, including autism.

The study did not receive any financial support, and we were not able to estimate any bias possibility during our analysis.

\section{References}

[1] Butaye, P., Devriese, L.A. and Haesebrouck, F. (2003) Antimicrobial Growth Promoters Used in Animal Feed: Effects of Less Well Known Antibiotics on Gram-Positive Bacteria. Clinical Microbiology Reviews, 16, 175-188. http://dx.doi.org/10.1128/CMR.16.2.175-188.2003

[2] Robinson, C.J. and Young, V.B. (2010) Antibiotic Administration Alters the Community Structure of the Gastrointestinal Micobiota. Gut Microbes, 1, 279-284. http://dx.doi.org/10.4161/gmic.1.4.12614

[3] Cani, P.D., Amar, J., Iglesias, M.A., Poggi, M., Knauf, C., Bastelica, D., et al. (2007) Metabolic Endotoxemia Initiates Obesity and Insulin Resistance. Diabetes, 56, 1761-1772. http://dx.doi.org/10.2337/db06-1491

[4] Cani, P.D., Bibiloni, R., Knauf, C., Waget, A., Neyrinck, A.M., Delzenne, N.M., et al. (2008) Changes in Gut Microbiota Control Metabolic Endotoxemia-Induced Inflammation in High-Fat Diet-Induced Obesity and Diabetes in Mice. Diabetes, 57, 1470-1481. http://dx.doi.org/10.2337/db07-1403

[5] Mansi, Y., Abdelaziz, N., Ezzeldin, Z. and Ibrahim, R. (2011) Randomized Controlled Trial of a High Dose of Oral Erythromycin for the Treatment of Feeding Intolerance in Preterm Infants. Neonatology, 100, 290-294. http://dx.doi.org/10.1159/000327536

[6] Ternak, G. (2005) Antibiotics May Act As Growth/Obesity Promoters in Humans as an Inadvertent Result of Antibiotic Pollution? Medical Hypotheses, 64, 14-16. http://dx.doi.org/10.1016/j.mehy.2004.08.003

[7] Gough E.K., Moodie, Erica, E.M., Prendergast, A.J., Johnson, S.M.A., Humphrey, J.H, Stoltzfus, R.J., et al. (2014) The Impact of Antibiotics on Growth in Children in Low and Middle Income Countries: Systematic Review and MetaAnalysis of Randomised Controlled Trials. British Medical Journal, 348, g2267. http://dx.doi.org/10.1136/bmj.g2267

[8] Cho, I., Yamanishi, S., Cox, L., Methé, B.A., Zavadil, J., Li, K., et al. (2012) Antibiotics in Early Life Alter Murine Colonic Microbiome and Adiposity. Nature, 488, 621-626. http://dx.doi.org/10.1038/nature11400

[9] Ajslev, T.A., Andersen, C.S., Gamborg, M., Sorensen, T.I. and Jess, T. (2011) Childhood Overweight after Establishment of the Gut Microbiota: The Role of Delivery Mode, Pre-Pregnancy Weight and Early Administration of Antibiotics. International Journal of Obesity (London), 35, 522-29. http://dx.doi.org/10.1038/ijo.2011.27

[10] Ray, K. (2012) Gut Microbiota: Adding Weight to the Microbiota’s Role in Obesity-Exposure to Antibiotics Early in Life Can Lead to Increased Adiposity. Nature Reviews Gastroenterology \& Hepatology, 11, 615. http://dx.doi.org/10.1038/nrgastro.2012.175

[11] Trasande, L., Blustein, J., Liu, M., Corwin, E., Cox, L.M. and Blaser, M.J. (2013) Infant Antibiotic Exposures and Early-Life Body Mass. International Journal of Obesity (London), 37, 16-23. http://dx.doi.org/10.1038/ijo.2012.132

[12] Goossens, H., Ferech, M., Vander Stichele, R. and Elseviers, M. (2005) ESAC Project Group. Outpatient Antibiotic Use in Europe and Association with Resistance: A Cross-National Database Study. Lancet, 365, 579-587. http://dx.doi.org/10.1016/S0140-6736(05)70799-6

[13] Versporten, A., Coenen, S., Adriaenssens, N., Muller, A., Minalu, G., Faes, C., et al., and On Behalf of the ESAC Project Group (2011) European Surveillance of Antimicrobial Consumption (ESAC): Outpatient Cephalosporin Use in Europe (1997-2009). Journal of Antimicrobial Chemotherapy, 66, vi25-vi35. http://dx.doi.org/10.1093/jac/dkr455

[14] Adriaenssens, N., Coene, S., Versporten, A., Muller, A., Minalu, G., Faes, C., et al., and on Behalf of the ESAC Project Group (2011) European Surveillance of Antimicrobial Consumption (ESAC): Outpatient Macrolide, Lincosamide and Streptogramin (MLS) Use in Europe (1997-2009). Journal of Antimicrobial Chemotherapy, 66, vi37-vi45. http://dx.doi.org/10.1093/jac/dkr456

[15] Adriaenssens, N., Coene, S., Versporten, A., Muller, A., Minalu, G., Faes, C., et al., and on Behalf of the ESAC Project Group (2011) European Surveillance of Antimicrobial Consumption (ESAC): Outpatient Quinolone Use in Europe (1997-2009). Journal of Antimicrobial Chemotherapy, 66, vi47-vi56. http://dx.doi.org/10.1093/jac/dkr457

[16] Versporten, A., Coenen, S., Adriaenssens, N., Muller, A., Minalu, G., Faes, C., et al., and on Behalf of the ESAC Project Group (2011) European Surveillance of Antimicrobial Consumption (ESAC): Outpatient Penicillin Use in Europe (1997-2009). Journal of Antimicrobial Chemotherapy, 66, vi13-vi23. http://dx.doi.org/10.1093/jac/dkr454

[17] OECD/European Union (2010) Overweight and Obesity among Children. In Health at a Glance: Europe 2010, OECD Publishing.

[18] Health at a Glance 2011 OECD Indicators, Overweight and Obesity among Children. 
[19] OECD (2012) Overweight and Obesity among Adults. In Health at a Glance: Europe 2012, OECD Publishing.

[20] OECD (2013) Health at a Glance 2013: OECD Indicators, OECD Publishing. http://dx.doi.org/10.1787/health_glance-2013-en

[21] WHO Report: Report on Modelling Adulthood Obesity across the WHO European Region, Prepared by Consultants (Led by T. Marsh and Colleagues) for the WHO Regional Office for Europe in 2013. http://www.euro.who.int/

[22] Breda, J. (2014) WHO. Childhood Obesity Surveillance Initiative http://www.euro.who.int/en/health-topics/disease-prevention/nutrition/activities/monitoring-and-surveillance/who-euro pean-childhood-obesity-surveillance-initiative-cosi

[23] Savvaa, S.C., Kouridesa, Y.A., Hadjigeorgioua, C. and Tornaritis, M.J. (2014) Overweight and Obesity Prevalence and Trends in Children and Adolescents in Cyprus 2000-2010. Obesity Research \& Clinical Practice, 8, e426-e434.

[24] Kootte, R.S., Vrieze, A., Holleman, F., Dallinga-Thie, G.M., Zoetendal, E.G., de Vos, W.M., et al. (2012) The Therapeutic Potential of Manipulating Gut Microbiota in Obesity and Type 2 Diabetes Mellitus. Diabetes, Obesity and Metabolism, 14, 112-120. http://dx.doi.org/10.1111/j.1463-1326.2011.01483.x

[25] Angelakis, E., Merhej, V. and Raoult, D. (2013) Related Actions of Probiotics and Antibiotics on Gut Microbiota and Weight Modification. The Lancet Infectious Diseases, 13, 889-899. http://dx.doi.org/10.1016/S1473-3099(13)70179-8

[26] Kang, D.W., Park, J.G., Ilhan, Z.E., Wallstrom, G., LaBaer, J., Adams, J.B. and Krajmalnik-Brown, R. (2013) Reduced Ncidence of Prevotella and Other Fermenters in Intestinal Microflora of Autistic Children. PLoS One, 8, e68322. http://dx.doi.org/10.1371/journal.pone.0068322

[27] Finegold, S.M., Downes, J. and Summanen, P.H. (2012) Microbiology of Regressive Autism. Anaerobe, 18, $260-262$. http://dx.doi.org/10.1016/j.anaerobe.2011.12.018

[28] Borody, T., Leis, S., Campbell, J., Torres, M. and Nowak, A. (2011) Fecal Microbiota Transplantation (FMT) in Multiple Sclerosis (MS). The American Journal of Gastroenterology, 106, S352.

[29] Vrieze, A., Van Nood, E., Holleman, F., Salojärvi, J., Kootte, R.S., Bartelsman, J.F., et al. (2012) Transfer of Intestinal Microbiota from Lean Donors Increases Insulin Sensitivity in Individuals with Metabolic Syndrome. Gastroenterology, 143, 913-916. http://dx.doi.org/10.1053/j.gastro.2012.06.031

[30] Jernberg, C., Lofmark, S., Edlund, C. and Jansson, J.K. (2007) Long-Term Ecological Impacts of Antibiotic Administration on the Human Intestinal Microbiota. The ISME Journal, 1, 56-66. http://dx.doi.org/10.1038/ismej.2007.3 